\title{
Penerapan Metode Rapid Application Development Dalam Sistem Informasi Pendidikan
}

\author{
Dony Oscar ${ }^{1}$, Jefi $^{2}$, Mayang Mentari Nur Arifia ${ }^{3}$ \\ 1,2,3 Universitas Bina Sarana Informatika \\ e-mail: ${ }^{1}$ dony.dor@bsi.ac.id, ${ }^{2}$ jefi.jfi@ bsi.ac.id, ${ }^{3}$ mayang.mentari@gmail.com

\begin{tabular}{ccc}
\hline Diterima & Direvisi & Disetujui \\
$13-12-2019$ & $15-12-2019$ & $17-12-2019$ \\
\hline
\end{tabular}

\begin{abstract}
Abstrak - SMA Raudhah Barmawiyah Kota Tangerang sebagai salah satu lembaga pendidikan sekolah swasta di kota Tangerang yang bertujuan untuk mendidik dan memberi pengetahuan baik berupa ilmu, sikap dan keahlian bagi para siswanya. Hal ini sudah berjalan secara berkelanjutan sehingga SMA Raudhah Barmawiyah mendapat reputasi dan memiliki fasilitas pendidikan yang baik.Sampai saat ini SMA Raudhah Barmawiyah masih menggunakan sistem manual, seperti pengolahan data siswa, guru, jadwal pelajaran, nilai siswa dan media penyimpanan masih dalam bentuk dokumen yang menggunakan microsoft word dan microsoft excel meskipun penataan tertata rapih tetapi beresiko kerusakan atau kehilangan data lebih tinggi.Menurut Jogiyanto dalam (Melan Susanti, 2016) "Sistem informasi adalah suatu sistem di dalam organisasi yang mempertemukan kebutuhan pengolahan transaksi harian, mendukung operasi, bersifat manajerial dan kegiatan strategi dari suatu organisasi dan menyediakan pihak luar tertentu dengan laporan - laporan yang di perlukan". Menurut Mishra dan Dubey dalam (Supriyatna, 2018) Untuk pengembangan suatu sistem informasi yang normal membutuhkan waktu minimal 180 hari. Namun dengan metode RAD suatu sistem dapat diselesaikan hanya dalam waktu 60-90 hari . Sistem Informasi Akademik ini ditujukan untuk mempermudah setiap pencarian data dengan cepat, dan solusi bagi SMA Raudhah Barmawiyah Tangerang ini membutuhkan sebuah sistem informasi akademik dengan sistem layanan pendidikan berbasis web yang dapat mengakses dan memperoleh informasi - informasi dengan lebih cepat.
\end{abstract}

Kata Kunci: website, sistem informasi, Rapid Application Development

\begin{abstract}
Abstrak - Raudhah Barmawiyah High School Tangerang City as one of the private school educational institutions in the city of Tangerang which aims to educate and provide good knowledge in the form of knowledge, attitudes and expertise for their students. This has been running continuously so that Raudhah Barmawiyah High School gets a reputation and has good educational facilities. Until now Raudhah Barmawiyah High School still uses manual systems, such as processing student data, teachers, lesson schedules, student grades and storage media in the form of documents using microsoft word and microsoft excel even though the orderly arrangement is neat but at risk of damage or loss of data is higher. According to Jogiyanto in (Melan Susanti, 2016) "Information systems are systems within organizations that bring together daily transaction processing needs, supporting operations, managerial and activities the strategy of an organization and provide certain outside parties with necessary reports. According to Mishra and Dubey in (Supriyatna, 2018) For the development of a normal information system requires a minimum of 180 days. But with the RAD method a system can be completed in just 60-90 days. The Academic Information System is intended to facilitate each data search quickly, and the solution for Tangerang's Raudhah Barmawiyah High School requires an academic information system with a web-based education service system that can access and obtain information faster.
\end{abstract}

Keywords: website, Information System, Rapid Application Development

\section{PENDAHULUAN}

SMA Raudhah Barmawiyah Kota Tangerang sebagai salah satu lembaga pendidikan sekolah swasta di kota Tangerang yang bertujuan untuk mendidik dan memberi pengetahuan baik berupa ilmu, sikap dan keahlian bagi para siswanya. Hal ini sudah berjalan secara berkelanjutan sehingga SMA Raudhah Barmawiyah mendapat reputasi dan memiliki fasilitas pendidikan yang baik.

Sampai saat ini SMA Raudhah Barmawiyah masih menggunakan sistem manual, seperti pengolahan data siswa, guru, jadwal pelajaran, nilai siswa dan media penyimpanan masih dalam bentuk dokumen yang menggunakan microsoft word dan microsoft excel meskipun penataan tertata rapih tetapi beresiko kerusakan atau kehilangan data lebih tinggi. Menurut Jogiyanto dalam (Susanti, 2016) "Sistem informasi adalah suatu sistem di dalam organisasi yang mempertemukan kebutuhan pengolahan transaksi harian, mendukung operasi, bersifat manajerial dan kegiatan strategi dari suatu organisasi 
dan menyediakan pihak luar tertentu dengan laporan - laporan yang di perlukan". Sistem Informasi Akademik ini ditujukan untuk mempermudah setiap pencarian data dengan cepat, dan solusi bagi SMA Raudhah Barmawiyah Tangerang ini membutuhkan sebuah sistem informasi akademik dengan sistem layanan pendidikan berbasis web yang dapat mengakses dan memperoleh informasi - informasi dengan lebih cepat.

\section{KAJIAN LITERATUR}

Menurut Raharjo dalam (Supriyanta \& Nisa, 2015) "World Wide Web (WWW), sering disingkat dengan web, adalah suatu layanan di dalam jaringan yang berupa ruang informasi".

\section{a. Website}

Menurut Setiadi dalam (Sari, 2017) "Website adalah sekumpulan halaman yang menampilkan konten atau sesuatu yang bisa diakses atau dibuka apabila kita mengakses internet".

\section{b. Web Browser}

Menurut Kasiman dalam (Melan Susanti, 2016) "Program untuk menampilkan halaman yang berbentuk kode HTML. Semua halaman web ditulis dengan bahasa HTML (Hypertext Mark Up Language), Walaupun beberapa file mempunyai ekstensi yang berbeda (contoh: .html, .php, .php3), output file - file tersebut tetap HTML. HTML adalah medium yang selalu dikirimkan ke web browser baik halaman itu berupa halaman statis, sebuah script (seperti PHP), ataupun yang dibuat oleh program CGI (Common Gateway Interface)".

\section{c. Web Server}

Menurut Fathansyah dalam (Agus Prayitno, 2015) "Menerangkan bahwa pengertian web server adalah "Server Web (Web Server) merujuk pada perangkat keras (server) dan perangkat lunak yang menyediakan layanan akses kepada pengguna melalui protokol komunikasi HTTP ataupun variannya (seperti FTP dan HTTPS) atas berkas berkas yang terdapat pada suatu URL ke pemakai”.

\section{d. PHP}

Menurut (Didik, 2017:54) "PHP sendiri sebenarnya singkatan dari "Hypertext Preprocessor", yang merupakan sebuah bahasa scripting tingkat tinggi yang dipasang pada dokumen HTM".

\section{e. Java Script}

Menurut Sidik dalam (Agus Prayitno, 2015) menjelaskan bahwa "JavaScript adalah bahasa pemrograman yang digunakan untuk membuat program yang digunakan agar dokumen HTML yang ditampilkan dalam browser menjadi lebih interaktif, tidak sekedar indah saja"

\section{f. Basis Data}

Menurut Connoly dan Begg dalam (Puspitasari, 2016) Basis data adalah kumpulan data yang saling berhubungan secara logikal serta deskripsi dari data tersebut, yang dirancang untuk memenuhi kebutuhan informasi suatu organisasi. Membangun basis data adalah langkah awal dari pembuatan sebuah aplikasi. Keberhasilan dalam membangun basis data akan menyebabkan program lebih mudah dibaca, mudah dikembangkan dan mudah mengikuti perkembangan perangkat lunak. Berikut ini adalah komponen komponen yang terdapat dalam basis data, yaitu : Tabel, Field, Record, Primary Key, Foreign Key dan Index.

\section{g. MySQL}

Menurut Arief dalam (Fridayanthie \& Mahdiati, 2016) "MySQL (MyStructure Query Languange) adalah salah satu jenis database server yang sangat terkenal dan banyak digunakan untuk membangun aplikasi web yang menggunakan database sebagai sumber dan pengelolaan datanya". MySQL bersifat open source dan menggunakan SQL (Structured Query Languange). MySQL biasa dijalankan diberbagai platform misalnya windows Linux, dan lain sebagainya.

\section{h. ERD}

Menurut Kroenke dalam (Haryani, 2015) "ERD (Entity Relationship Diagram) adalah suatu pemodelan konseptual yang didesain secara khusus untuk mengidentifikasikan entitas yang menjelaskan data dan hubungan antar data, yaitu dengan menuliskan dalam cardinality". Elemen - elemen yang membentuk ERD diantaranya :

1) Entity yaitu suatu entitas yang dapat berupa orang, tempat, obyek, atau kejadian yang dianggap penting bagi perusahaan, sehingga segala atributnya harus dicatat dan disimpan dalam basis data.

2) Attribute. Setiap entitas mempunyai karakterisik tertentu yang dinamakan dengan atribut. Contoh dari attribute adalah Employee Name, Customer Name, Employee ID dan Customer ID.

3) Identifier merupakan nama attribute yang digunakan untuk mengidentifikasi entity. Ada tiga jenis identifier, yaitu Primary Key, Secondary Key dan Foreign Key.

4) Relationship merupakan hubungan suatu jalinan antara entitas.

5) Cardinality merupakan kendala - kendala yang timbul dalam hubungan antar entitas.

\section{i. LRS}

Menurut Frieyadie dalam (Zamaludin, Yusnaeni, Amelia, Pengembangan, \& Lunak, 2016) "LRS kepanjangan dari Logical Record Structure merupakan hasil dari pemodelan Entity Relationship (ER) berserta atributnya sehingga bisa terlihat hubungan - hubungan antara entitas". Dalam 
pembuatan LRS terdapat tiga hal yang dapat mempengaruhi, yaitu:

1) Jika tingkat hubungan (cardinality) satu pada satu (one-to-one), maka digabungkan dengan entitas yang lebih kuat (strong entity), atau digabungkan dengan entitas yang memiliki atribut yang lebih sedikit.

2) Jika tingkat hubungan (cardinality) satu pada banyak (one-to-many), maka hubungan relasi atau digabungkan dengan entitas yang tingkat hubungannya banyak.

3) Jika tingkat hubungan (cardinality) banyak pada banyak (many-to-many), maka hubungan relasi tidak akan digabungkan dengan entitas manapun, melainkan menjadi sebuah LRS.

\section{METODE PENELITIAN}

$\begin{array}{rrrr}\text { Metode } & \text { pengembangan } & \text { sistem Rapid } \\ \text { Application } & \text { Development } & \text { merupakan }\end{array}$
pengembangan dengan waktu yang relatif cepat dan singkat. Menurut Mishra dan Dubey dalam (Supriyatna, 2018) Untuk pengembangan suatu sistem informasi yang normal membutuhkan waktu minimal 180 hari. Namun dengan metode RAD suatu sistem dapat diselesaikan hanya dalam waktu 60-90 hari

Metode RAD memiliki fase-fase melakukan perencanaan syarat-syarat kebutuhan sistem, melibatkan pengguna untuk merancang sistem dan membangun sistem (kegiatan ini dilakukan secara berulang-ulang hingga mencapai kesepakatan bersama), dan terakhir tahap implementasi.

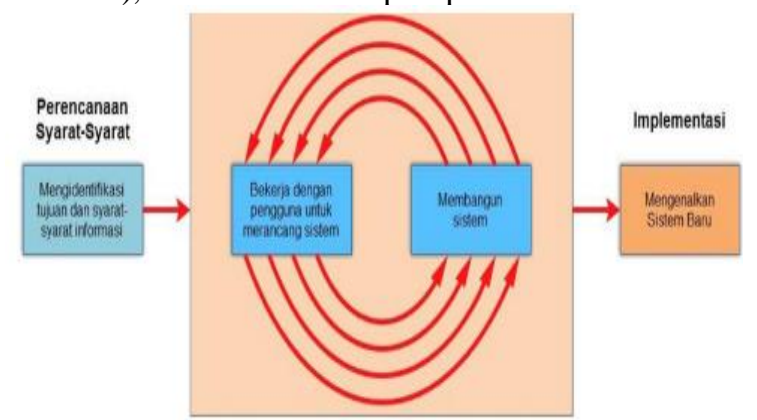

Sumber : Mishra dan Dubey dalam (Supriyatna, 2018)

\section{Gambar 1. Model RAD}

Menurut Kendal \& Kendal dalam (Susilowati $\&$ Tirta negara, 2018) terdapat empat fase yang ada pada metode RAD dan pada tahap penilaian melibatkan penganalisis dan pengguna

yaitu :

\section{Fase Requirements Planing}

ini merupakan fase pertama dalam pengembangan sistem. Pada tahap ini pertemuan antara analis dan pengguna mengidentifikasikan tujuan dari system yang akan dibangun kemudian mengidentifikasi syarat-syarat infromasi yang akan muncul untuk mencapai tujuan tersebut serta menganalisa semua sistem yang akan dibutuhkan oleh pengguna

\section{Fase RAD Design Workshop}

Pada fase kedua ini merupakan fase dalam bentuk workshop antara analis dan programmer untuk berkerjasama dalam merancang dan membangun sistem yang kemudian akan menunjukan representasi nya dalam bentuk visual desain dan pola kerja kepada pengguna sistem. Analis dan programmer dapat melakukan perbaikan dan meganalisa modul modul yang telah di rancang berdasarkan respon dari pengguna sistem.

\section{Fase Instruction (Konstruksi)}

Tahapan ini merumakan fase eksekusi dari fase sebelumnya. Di fase ini akan menunjukan platform, hardware dan juga software yang akan digunakan dalam pengembangan sistem. Desain - desain yang telah di buat pada fase sebelum nya akan ditingkatkan dengan menggunakan perangkat RAD. Saat fungsi baru tersedia, fungsi tersebut akan ditunjukan kepada pengguna sistem untuk mendapatkan interaksi dan revisi, selanjutnya analis akan melakukan perubahan dalam setiap desain aplikasi berdasarkan instruksi dari pengguna

\section{Fase Imlementation (Implementasi)}

Pada fase ini analis berkerja sama dengan pengguna sistem secara itensif di dalam workshop yang berlangsung untuk merancang beberapa aspek nonteknis yang dibutuhkan. Setelah aspek -aspek ini disetujui dan sistem-sistem telah dibangun dan disaring, sistem-sistem baru tersebut akan diuji coba dan kemudian akan diperkenalkan kepada organisasi.

\section{HASIL DAN PEMBAHASAN}

\section{Fase Requirements Planing}

Analisa kebutuhan sistem yang akan digunakan pada website SMA Raudhah Barmawiyah adalah sebagai berikut

Tabel 1. Analisa kebutuhan Administrator

\begin{tabular}{|c|l|}
\hline No & \multicolumn{1}{|c|}{ Kebutuhan Pengguna } \\
\hline 1 & Login Administrator \\
\hline 2 & $\begin{array}{l}\text { Kelola data siswa, guru, mata pelajaran, ruang } \\
\text { kelas, jadwal pelajaran, nilai }\end{array}$ \\
\hline 3 & Tambah administrator \\
\hline 4 & Ganti password \\
\hline 5 & Kelola data administrator \\
\hline 6 & Ruang home administrator \\
\hline
\end{tabular}

Sumber : penelitian 2019

Tabel 2. Analisa kebutuhan Guru

\begin{tabular}{|c|l|}
\hline No & \multicolumn{1}{|c|}{ Kebutuhan pengguna } \\
\hline 1 & Login guru \\
\hline 2 & Ruang home guru \\
\hline
\end{tabular}




\begin{tabular}{|l|l|}
\hline 3 & Melihat jadwal mengajar \\
\hline 4 & Input data nilai \\
\hline 5 & Melihat nilai \\
\hline 6 & Kelola biodata guru \\
\hline 7 & Ganti password \\
\hline
\end{tabular}

Sumber : penelitian 2019

Tabel 3. Analisa kebutuhan Siswa

\begin{tabular}{|c|l|}
\hline No & \multicolumn{1}{|c|}{ Kebutuhan Pengguna } \\
\hline 1 & Login siswa \\
\hline 2 & Ruang home siswa \\
\hline 3 & Melihat nilai siswa \\
\hline 4 & Melihat jadwal pelajaran \\
\hline 5 & Melihat data siswa \\
\hline 6 & Ganti password \\
\hline
\end{tabular}

Sumber : penelitian 2019

\section{Fase RAD Design Workshop}

Pada tahap ini akan dilakukan perancangan sistem. Dalam pelaksanaannya penulis melakukan perancangan sistem dan perancangan basis data.

\section{a. Desain sistem}

Pada rancangan ini penenulis menggunakan Unified Modelling Language atau UML, Rancangan sistem terdiri dari 3 level pengguna yaitu administrator, guru dan siswa.

1) Use Case Administrator

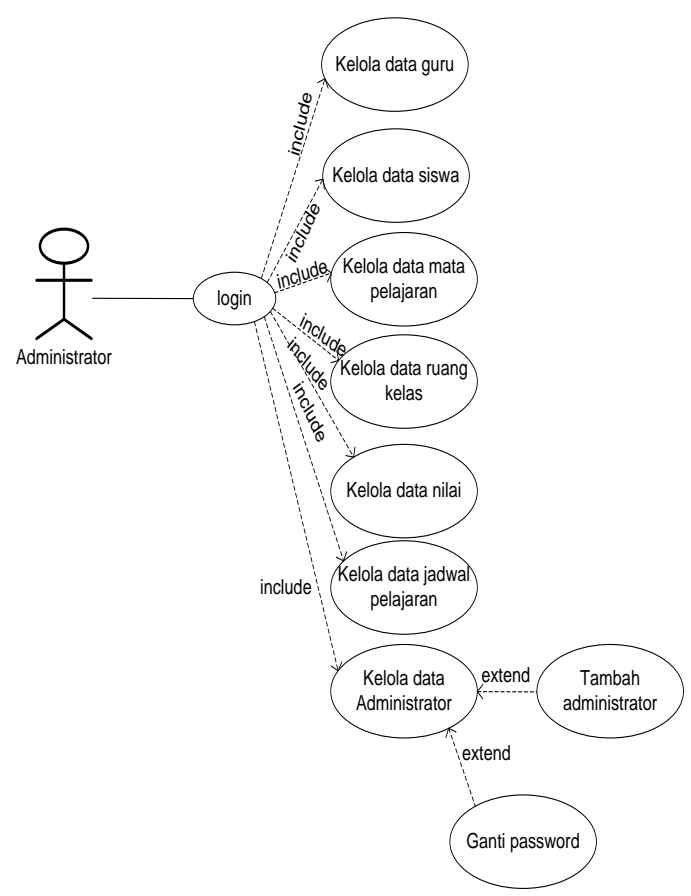

Sumber : penelitian 2019

Gambar 2. Use case administrator

\section{2) Use Case Guru}

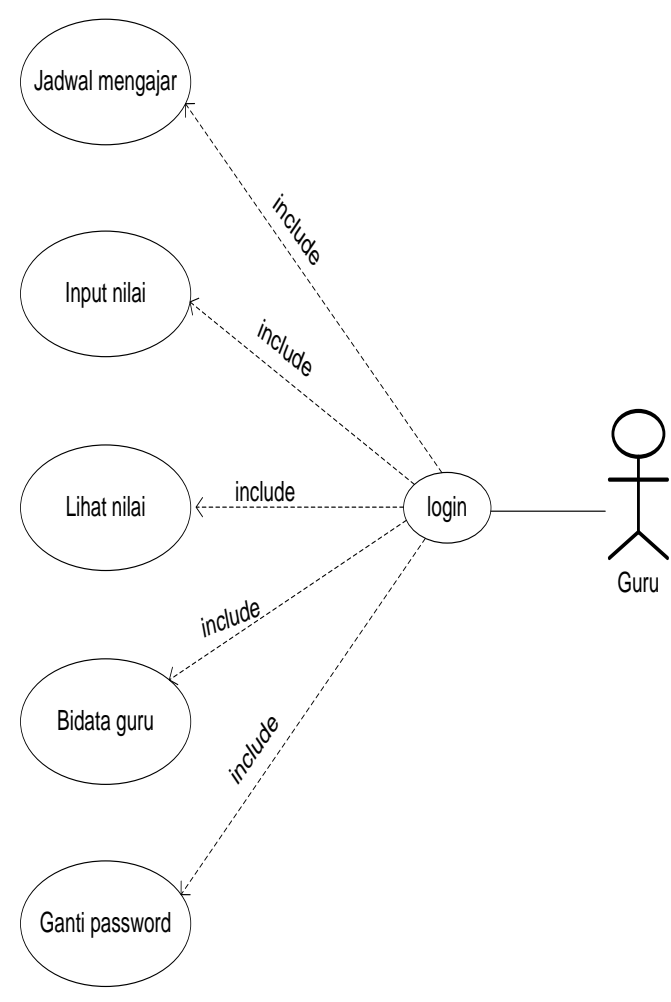

Sumber : penelitian 2019

Gambar 3. Use case Guru

3) Use Case Siswa

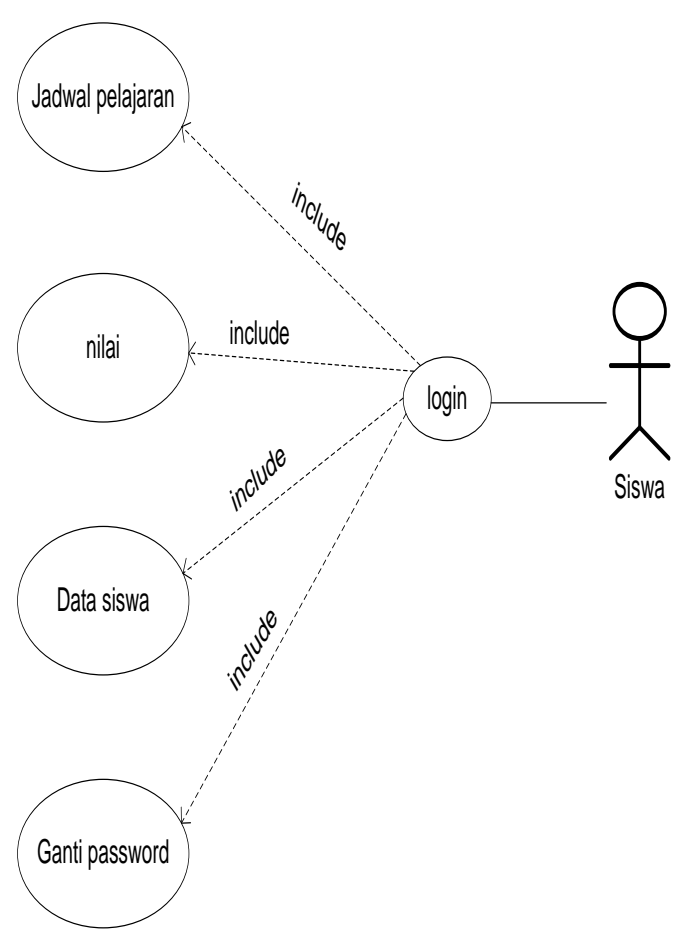

Sumber : penelitian 2019

Gambar 4. Use case Siswa 
b. Desain basis data

1) Entity Relationship Diagram

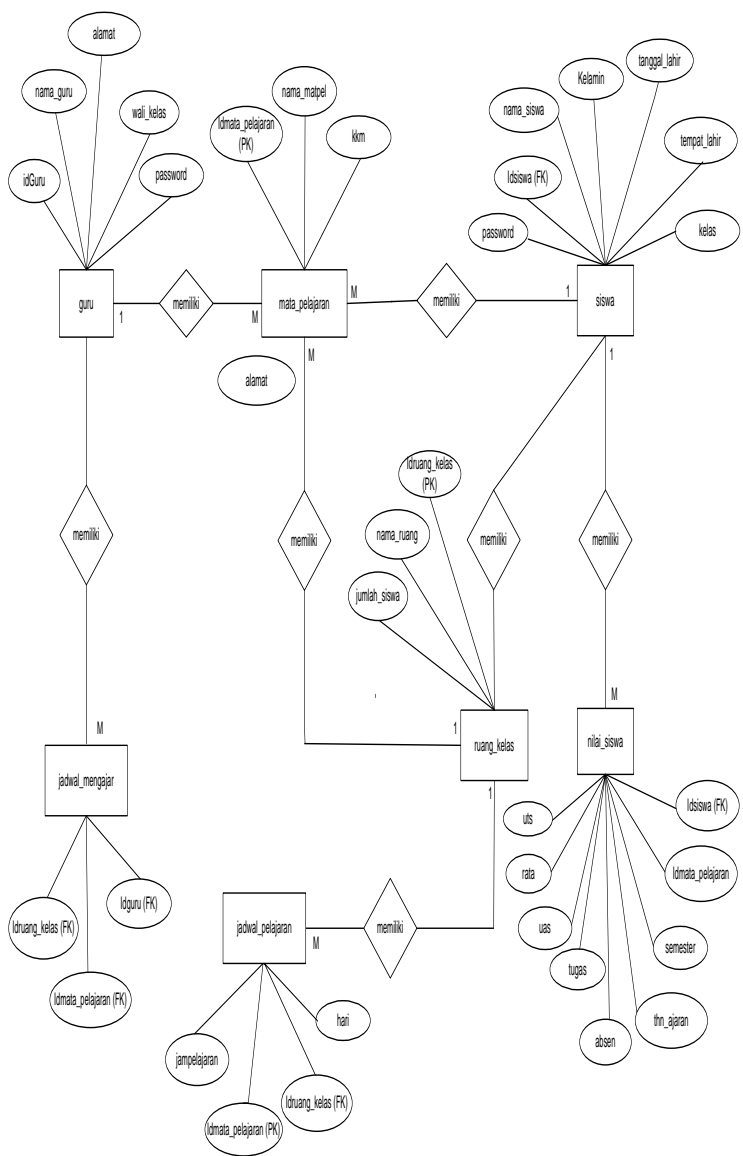

Sumber : penelitian 2019

Gambar 5. ERD Sistem Informasi akademik SMA RaudhahBarmawiyah

2) Logical Record Structure

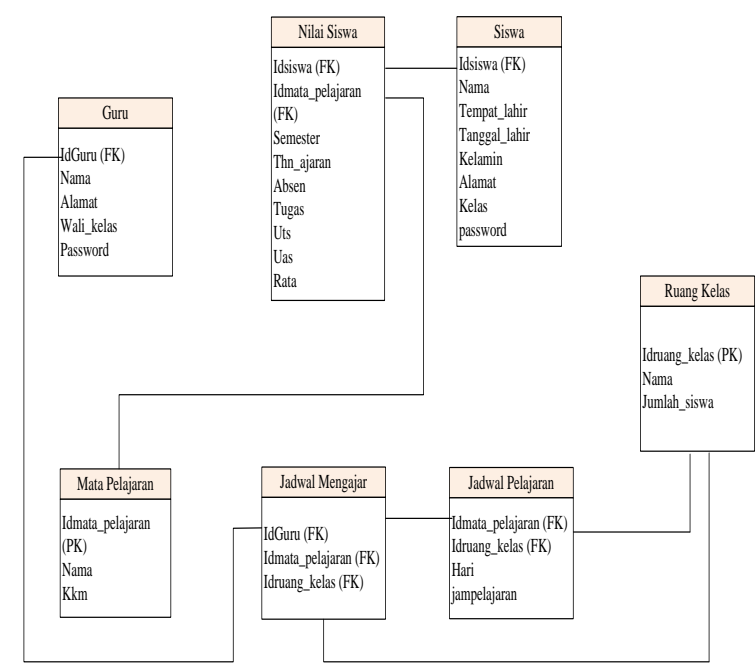

Sumber : penelitian 2019

\section{Gambar 6. LRS Sistem Informasi akademik SMA RaudhahBarmawiyah 3. Fase Instruction (Konstruksi)}

Di fase ini akan dilakukan pembuatan script program berdasarkan pada desain yang sudah dibuat sebelumnya dengan menggunakan beberapa Bahasa pemrograman seperti php, javasript, html dan menggunakan query sql.

\section{Fase Implementation (Implementasi)}

Pada fase ini dilakukan implementasi sistem yang telah dibuat kemudian pada fase ini juga dilakukan testing terhadap sistem yang baru dengan tujuan untuk dapat mengetahui apakah sistem telah berjalan dengan baik atau diperlukan perbaikan kembali.

a. Implementasi Halaman home administrator Halaman administrator ini hanya dapat digunakan oleh administrator. Halaman ini digunakan untuk pengelolaan konten web.

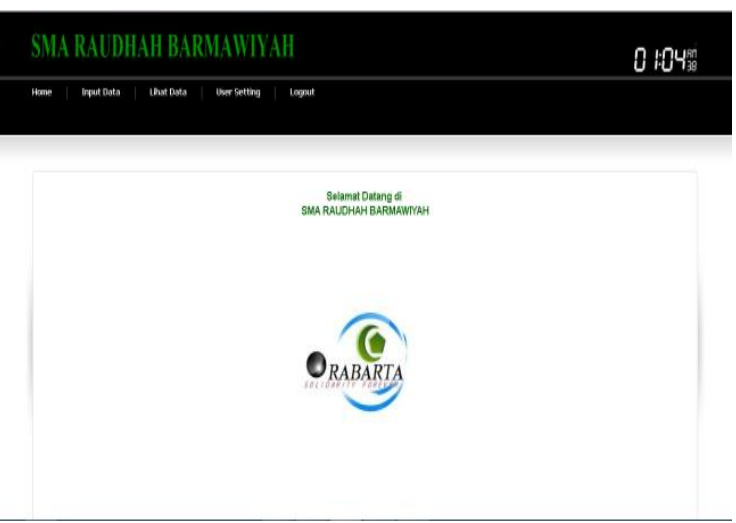

Sumber : penelitian 2019

\section{Gambar 7. Halaman home administrator}

b. Implementasi halaman home guru

Halaman ini digunakan oleh guru untuk melihat jadwal mengajar, melakukan proses peninputan nilai siswa.

\section{SMA RAUDHAH BARMAWIYAH}

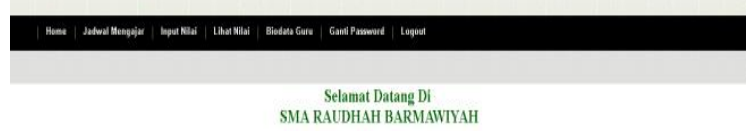

Sumber : penelitian 2019 


\section{Gambar 8. Halaman home guru}

c. Implementasi halaman home siswa

Halaman ini digunakan oleh siswa untuk melihat jadwal mata pelajaran, melihat nilai

SMA RAUDHAH BARMAWIYAH

Selamat Datang Di
SMA RAIDHAH BARMAWIYAH

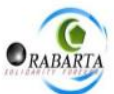

Sumber : penelitian 2019

\section{Gambar 9. Halaman home siswa}

d. Pengujian Unit

Pengujian sistem dilakukan dengan menggunakan metode black box testing.

Tabel 4. Hasil pengujian black box testing halaman login administrator

\begin{tabular}{|c|c|c|c|c|c|}
\hline No & $\begin{array}{l}\text { Skenario } \\
\text { Pengujian }\end{array}$ & $\begin{array}{l}\text { Test } \\
\text { Case }\end{array}$ & $\begin{array}{l}\text { Hasil yang } \\
\text { diharapkan }\end{array}$ & $\begin{array}{c}\text { Hasil } \\
\text { pengujian }\end{array}$ & $\begin{array}{c}\text { Kesi } \\
\text { mpula } \\
\text { n }\end{array}$ \\
\hline 1. & $\begin{array}{l}\text { Username } \\
\text { dan } \\
\text { password } \\
\text { tidak diisi } \\
\text { kemudia } \\
\text { klik login. }\end{array}$ & $\begin{array}{l}\text { Usern } \\
\text { ame: } \\
\text { (koso } \\
\text { ng) } \\
\text { Passw } \\
\text { ord: } \\
\text { (koso } \\
\text { ng) }\end{array}$ & $\begin{array}{l}\text { Sistem akan } \\
\text { mengeluarka } \\
\mathrm{n} \text { pesan } \\
\text { "login gagal" }\end{array}$ & $\begin{array}{l}\text { Sesuai } \\
\text { harapan }\end{array}$ & Valid \\
\hline 2. & $\begin{array}{l}\text { Mengetika } \\
\mathrm{n} \\
\text { username } \\
\text { dan } \\
\text { password } \\
\text { tidak diisi } \\
\text { atau } \\
\text { kosong } \\
\text { kemudian } \\
\text { klik } \\
\text { tombol } \\
\text { login. }\end{array}$ & $\begin{array}{l}\text { Usern } \\
\text { ame: } \\
\text { (admi } \\
\text { n) } \\
\text { Passw } \\
\text { ord: } \\
\text { (koso } \\
\text { ng) }\end{array}$ & $\begin{array}{l}\text { Sistem akan } \\
\text { mengeluarka } \\
\mathrm{n} \quad \text { pesan } \\
\text { "login gagal" }\end{array}$ & $\begin{array}{l}\text { Sesuai } \\
\text { harapan }\end{array}$ & Valid \\
\hline 3. & $\begin{array}{l}\text { Username } \\
\text { tidak diisi } \\
\text { (kosong) } \\
\text { dan } \\
\text { password } \\
\text { diisi } \\
\text { kemudian } \\
\text { klik login. }\end{array}$ & $\begin{array}{l}\text { Usern } \\
\text { ame: } \\
\text { (koso } \\
\text { ng) } \\
\text { Passw } \\
\text { ord: } \\
\text { (admi } \\
\text { n) }\end{array}$ & $\begin{array}{l}\text { Sistem akan } \\
\text { mengeluarka } \\
\mathrm{n} \quad \text { pesan } \\
\text { "login gagal" }\end{array}$ & $\begin{array}{l}\text { Sesuai } \\
\text { harapan }\end{array}$ & Valid \\
\hline 4. & $\begin{array}{l}\text { Mengetika } \\
\mathrm{n} \\
\text { username } \\
\text { dan } \\
\text { password } \\
\text { dengan } \\
\text { data yang } \\
\text { benar } \\
\text { kemudian } \\
\text { klik login. }\end{array}$ & $\begin{array}{l}\text { Usern } \\
\text { ame: } \\
\text { (admi } \\
\text { n) } \\
\text { Passw } \\
\text { ord: } \\
\text { (admi } \\
\text { n) }\end{array}$ & $\begin{array}{l}\text { Sistem } \\
\text { menerima } \\
\text { akses dan } \\
\text { menampilkan } \\
\text { "Selamat } \\
\text { Datang" } \\
\text { kemudian } \\
\text { menampilkan } \\
\text { home. }\end{array}$ & $\begin{array}{l}\text { Sesuai } \\
\text { harapan }\end{array}$ & Valid \\
\hline
\end{tabular}

Sumber : penelitian 2019

\section{KESIMPULAN}

Penerapan website pada sekolah menengah atas raudhah barmawiyah kota tanggerang dapat membantu proses belajar dan mengajar. Dengan ada nya website ini guru dan siswa menjadi terbantu terutama dalam proses input nilai dan jadwal belajar dan mengajar. Dengan langkah-langkah yang terdapat pada metode Rapid Application Development atau RAD yang diterapkan dalam pembangunan sistem mepermudah dalam proses pengembangan sistem. Untuk pengembangan website selanjut nya pihak sekolah dapat menambahkan fasilitas untuk orang tua atau wali siswa sehingga orang tua atau wali siswa dapat ikut memantau perkembangan Pendidikan anak - anak mereka

\section{REFERENSI}

Agus Prayitno, Y. S. (2015). Volume 1 No 1 - 2015 Lppm3.bsi.ac.id/jurnal IJSE - Indonesian Journal on Software Engineering. IJSE Indonesian Journal on Software Engineering, 1(1), 1-10.

Didik, S. (2017). BUKU SAKTI PEMOGRAMAN WEB: HTML, CSS, PHP, MYSQL \& Javascript (1st ed.). Yogyakarta: START UP.

Fridayanthie, E. W., \& Mahdiati, T. (2016). Rancang Bangun Sistem Informasi Permintaan Atk Berbasis Intranet (Studi Kasus: Kejaksaan Negeri Rangkasbitung). Jurnal Informatika, $4(2), 126-137$.

Haryani. (2015). Pemanfaatan Web Sistem Informasi Akademik Sebagai Pengontrol Nilai Siswa (Studi Kasus) Mts Modern Al-Islam Nganjuk. Paradigma, 17(2), 50-58.

Melan Susanti. (2016). Perancangan Sistem Informasi Akademik Berbasis Web Pada Smk Pasar Minggu Jakarta. Informatika, 3(1), 9199. https://doi.org/10.31311/JI.V3I1.304

Puspitasari, D. (2016). Sistem Informasi Perpustakaan Sekolah Berbasis Web. Jurnal Pilar Nusa Mandiri, 12(2), 227-240.

Sari, A. M. (2017). APLIKASI SITUS WEB PENJUALAN HIJAB ONLINE. Paradigma, 19(2).

Supriyanta, \& Nisa, K. (2015). Perancangan Website Desa Wisata Karangrejo Sebagai Media Informasi dan Promosi. Bianglala Informatika, 3(1), 35-40.

Supriyatna, A. (2018). Sistem Informasi Forum Diskusi Programmer Berbasis Web Menggunakan Rapid Application Development. 7(November), 138-147.

Susilowati, S., \& Tirta negara, M. (2018). IMPLEMENTASI MODEL RAPID APLICATION DEVELOPMENT ( RAD ). 15(1), 25-30.

Zamaludin, I., Yusnaeni, W., Amelia, S., Pengembangan, A. M., \& Lunak, P. (2016). Bahasa Jerman Berbasis Web. 3(2). 